\title{
Um turista bem moderno: a expressão amazônica de Mário de Andrade na literatura e na fotografia
}

\author{
Marcia Langfeldt (Université Sorbonne Nouvelle - Paris 3)
}

\begin{abstract}
Mário de Andrade (1893-1945) was a Brazilian poet, novelist, literary critic, ethnographer, musicologist, art critic as well as a competent photographer and a dedicated researcher of Brazilian folklore. In 1927, he travelled to the Amazon together with three female friends. During this trip, he published a series of articles in a national newspaper, wrote two diaries, collected notes and finished his most important book, Macunaima, considered the reference of Brazilian Modernism. In addition to that, he took more than 500 photos of the journey, most of them in a very modern perspective. This paper investigates to what extent these various representations of the Amazon contribute to Mario de Andrade's aesthetic project, as a Brazilian intellectual from the first quarter of the twentieth century.
\end{abstract}

Keywords: Amazon, travel writings, Mario de Andrade, Brazilian Literature, photography

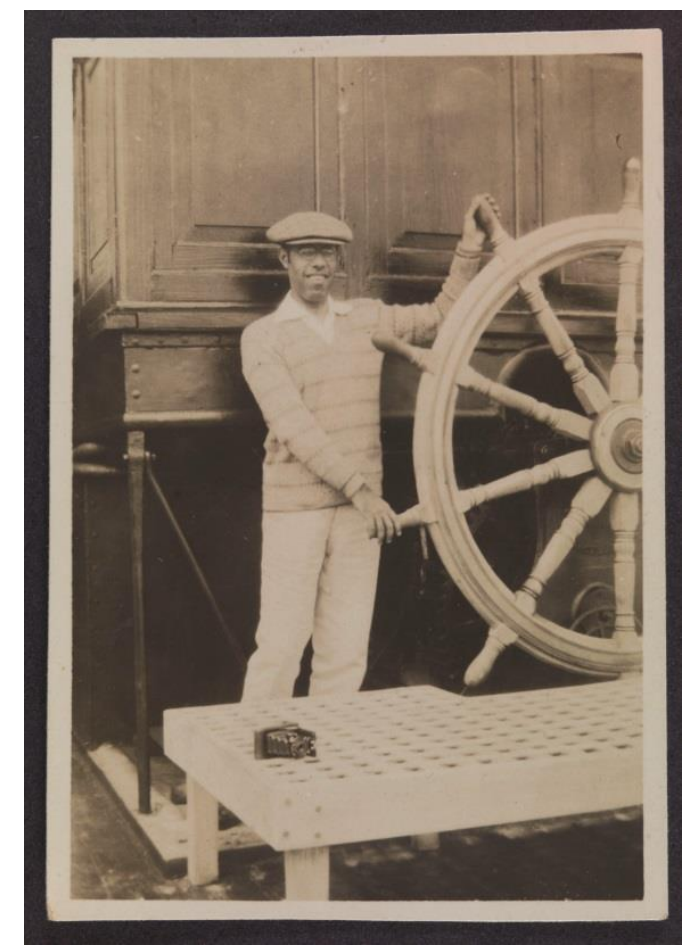

Fig. 1. Mário de Andrade na Amazônia (1927), com sua câmera Kodak em destaque.

Arquivo IEB - USP, Coleção MA (Propriedade dos herdeiros)

Se fôssemos a Marte e a Vênus conservando os mesmos sentidos, eles revestiriam do mesmo aspecto que têm as coisas da Terra tudo o que pudéssemos ver. A única viagem verdadeira, o único banho de Juventa, seria não partir em demanda de novas paisagens, 
mas ter outros olhos, ver o universo com os olhos de outra pessoa, de cem pessoas, ver os cem universos que cada uma delas vê, que cada uma delas é. (Proust)

No decorrer de 1927, o escritor brasileiro Mário de Andrade (1893-1945) visitou a Amazônia como turista. De um modo geral, as diversas viagens que realizou pelo país representaram importantes fontes de informação e inspiração para o autor, que dedicou a vida ao conhecimento e à valorização da cultura do seu país. Foi, portanto, com esta dupla finalidade que Mário de Andrade partiu de São Paulo, onde residia e trabalhava como professor do Conservatório de Música, para os confins da mata amazônica, viajando pela costa brasileira até Belém, no Pará, e depois seguindo pelos rios da região, como o Amazonas, o Negro, o Solimões e o Madeira, chegando até o Peru e a Bolívia.

Durante o périplo, ele dividiu o seu tempo entre o trabalho de revisão de um livro; a redação de um diário, que seria publicado em parte por um jornal paulista; a coleta de dados sobre o folclore e os costumes locais e o registro dos aspectos da vida naquela região, além da criação de uma narrativa ficcional envolvendo as três companheiras de viagem, que seria publicada postumamente. Além dos registros textuais, Mário de Andrade captou cerca de 500 imagens sobre a região. Com o amplo material que coletou na Amazônia, ele chegou a planejar a publicação de um relato de viagem que lhe ocupou pouco mais de uma década, projeto jamais concluído. Quando o escritor morreu subitamente, aos 51 anos, o tencionado livro continha um prefácio e um título: «O turista aprendiz: viagens pelo Amazonas até o Peru, pelo Madeira até a Bolívia e por Marajó até dizer chega! ». Este material, porém, só seria publicado muitos anos após a morte do escritor, em 1976, por pesquisadores brasileiros, à frente Telê Ancona Lopez, que há cinco décadas tem se dedicado ao estudo da vida e da obra deste autor, intitulado simplesmente $O$ turista aprendiz (1976).

Mário de Andrade foi um intelectual de múltiplas frentes de atuação: poeta, romancista, crítico literário, etnógrafo, musicólogo e crítico de artes, além de profundo pesquisador do folclore brasileiro e, como se poderá observar neste artigo, um criativo fotógrafo. Pensador engajado com o seu país e com o seu tempo, Andrade foi um dos organizadores da Semana de Arte Moderna, em 1922. Posteriormente, ele dirigiu o Departamento de Cultura do município de São Paulo, entre 1935 e 1938, onde concebeu e planejou a Biblioteca Municipal, implantou a Discoteca Pública e organizou uma missão de pesquisa folclórica ao Nordeste do país. Em 1936, a pedido do ministro Gustavo Capanema, redigiu o anteprojeto de criação do que veio a ser o atual Instituto do Patrimônio Histórico e Artístico Nacional (Iphan). Durante toda a sua vida, colecionou um vasto acervo, que é patrimônio do Instituto de Estudos Brasileiros da Universidade de São Paulo (IEB), desde 1968. O conjunto é constituído por uma biblioteca com mais de 17 mil volumes e 30 mil documentos e por três coleções: de artes plásticas, de arte religiosa e de arte popular. Esta volumosa coletânea de itens tem sido fonte inesgotável de pesquisas sobre a vida e a obra do escritor.

Tendo em vista isso, a citação do escritor francês Marcel Proust que abre este artigo, acerca da capacidade que têm os artistas de sair de si e ver o mundo com outros olhos, é, de fato, bastante apropriada ao caso específico de Mário de Andrade. Atrás das lentes dos seus óculos perfeitamente circulares, simultaneamente anteparo ótico e marca registrada do homem que tomava a vida com uma eterna descoberta, estava um viajante incomum. Levando consigo o caderno de notas e a câmera Kodak, Mário de Andrade assimilava a paisagem e a recriava. $\mathrm{O}$ aprendiz de turista de fato almejava apreender o meio circundante: ele admirava as pessoas e o mundo daquela posição privilegiada, capaz de ver o mundo com cem olhos, ou, 
como ele afirmou em um poema, com trezentos e cinquenta. (Andrade 1966, 157). Deste modo, o objetivo deste artigo é averiguar em que medida a viagem do autor à Amazônia dialoga com o restante do seu trabalho, e, em particular, de que maneira os registros que ele produziu durante o trimestre que passou na região, tanto os textuais quanto os visuais, estão inseridos dentro do seu projeto literário e artístico.

É a partir de suas pesquisas etnológicas que o escritor começa a se interessar pela região, no início da década de 1920, até que, em 1927, ele viaja à Amazônica, junto com Olívia Guedes Penteado, a sobrinha desta, Margarida Guedes Penteado e de Dulce do Amaral Pinto, filha da pintora Tarsila do Amaral. As companheiras de viagem ganham os apelidos de, respectivamente, Nossa Senhora do Brasil (Olívia foi importante mecenas do grupo modernista), Mag e Dolur. Na narrativa ficcional que criou envolvendo o trio, o autor as chamou de Manacá, Balança e Trombeta. Trata-se de uma novela, publicada em 1994, intitulada Balança, Trombeta e Battleship ou o descobrimento da alma.

De um modo geral, o seu método operacional consistia em pesquisar previamente sobre as regiões que visitaria, como uma forma de preparação do espírito para as impressões que iria receber. Sendo assim, a região amazônica surge na obra de Mário de Andrade em um período bem anterior ao ano da viagem. No início, ele idealiza uma Amazônia utópica que, por estar no interior do país, distante do litoral e das influências estrangeiras, de certo modo simbolizaria um gérmen do Brasil «autêntico ». Ele lamenta, ademais, conhecer o país pelos livros e não pessoalmente, como se nota neste trecho de «Acalanto do seringueiro », o segundo dos « Dois poemas acreanos » que ele escreveu em 1925:

\footnotetext{
Seringueiro, eu não sei nada!

E no entanto estou rodeado

Dum despotismo de livros,

Estes mumbavas que vivem

Chupitando vagarentos

$\mathrm{O}$ meu dinheiro o meu sangue

E não dão gosto de amor...

Me sinto bem solitário

No mutirão de sabença

Da minha casa, amolado

Por tantos livros geniais,

«Sagrados» como se diz...

E não sinto os meus patrícios!

E não sinto os meus gaúchos!

Seringueiro, dorme...

E não sinto os seringueiros

Que amo de amor infeliz...

(Andrade 2013, 259)
}

Ao longo da incursão ao Norte do Brasil, com o objetivo de ganhar uma remuneração extra, ele escreve artigos para o jornal Diário Nacional, no formato de um diário de viagem, cujos trechos serão reaproveitados pelo autor, em uma versão datiloscrita do que seria o mencionado livro com estes relatos, em 1943. (Andrade 2015, 25)

As cinco centenas de fotografias que ele captou na região amazônica foram sistematicamente organizadas e legendadas pelo próprio autor, tanto durante a viagem, quanto durante as duas décadas que se seguiram a esta. Sendo um crítico de artes, é fato de destaque 
que a fotografia surge na obra de Mário de Andrade mais como ferramenta de experimentação estética do que como objeto de documentação, embora ele tenha igualmente feito registros com esta finalidade. A este respeito, é importante ressaltar que Mário de Andrade tinha um amplo conhecimento das linguagens de vanguarda do período, com as quais buscava dialogar, como veremos a seguir.

Ora, ocorre que a arte da fotografia era relativamente pouco conhecida no Brasil no início da década de 1920. Em 1923, Mário de Andrade adquire uma câmera Kodak e assina algumas revistas de arte, como a publicação Der Querschnitt (seção transversal).

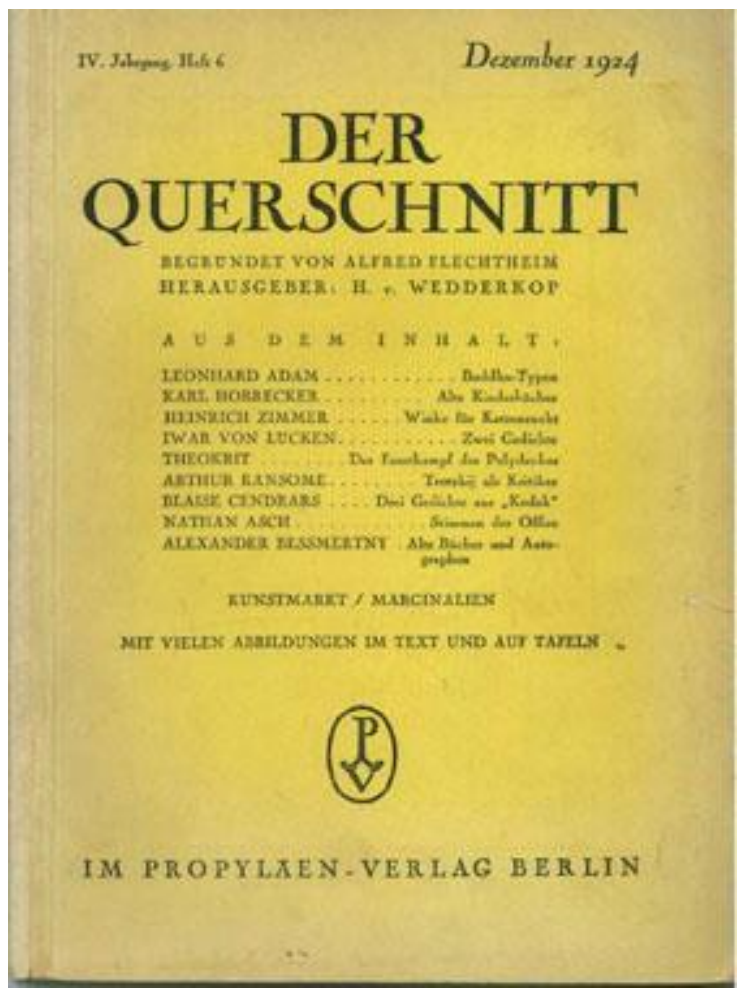

Fig. 2. Berlin: Galerie Flechtheim, 1921-1936

Tratava-se de uma revista alemã de arte de vanguarda, veiculada entre 1921 e 1934, na qual constava a colaboração de importantes escritores literários, artistas plásticos e fotógrafos. Ao compararmos diversos registros desta publicação com as imagens produzidas por Mário de Andrade, é possível perceber certas aproximações. De fato, o aprendiz de turista mostra-se um ávido aprendiz da arte fotográfica, utilizando a paisagem amazônica como tema. De um modo geral, os registros fotográficos do escritor paulista são exemplares da linguagem vanguardista, com planos inusitados, imagens cortadas ou incompletas, jogos de luz e sombra que criam efeitos geométricos, superposições, que sugerem o movimento ou aludem à fantasia e ao lírico e dialogam com outras obras de arte, com um forte acento impressionista e, em algumas ocasiões, surrealistas, como é o caso desta foto da escotilha do navio, que ele fez quando navegava no litoral baiano. 


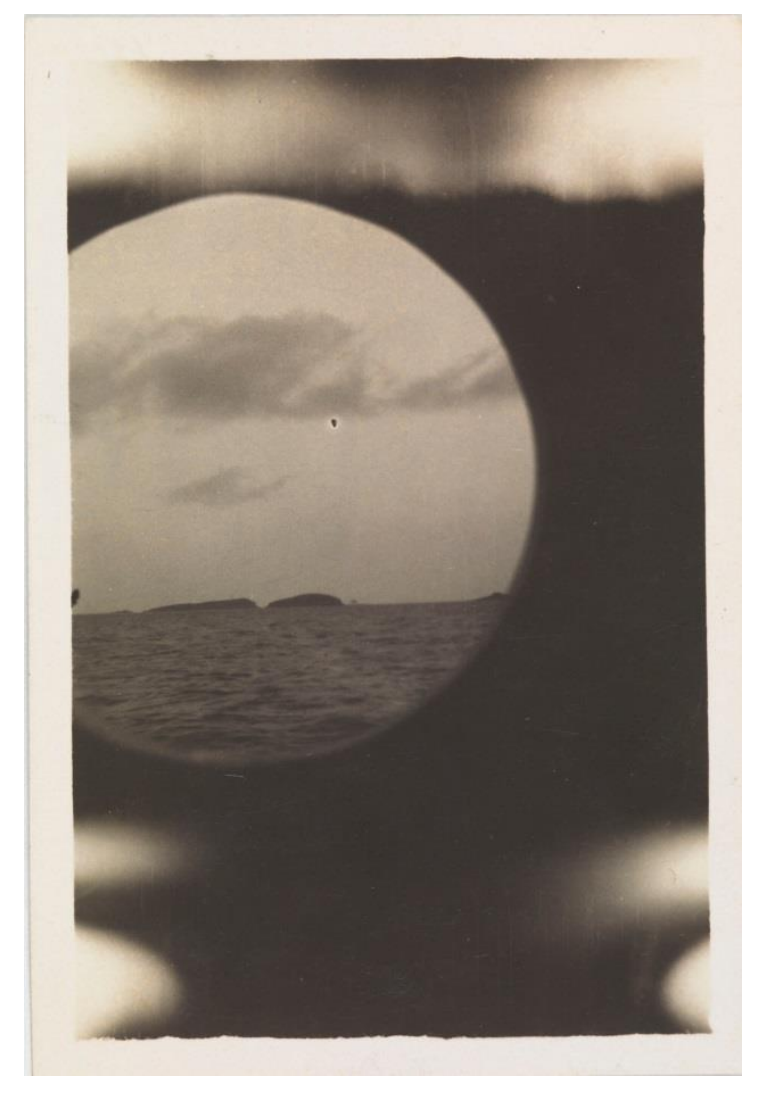

Fig. 3

Com relação à intenção do fotógrafo, destacam-se pelo menos três objetivos diferentes: em primeiro lugar, há a utilização da fotografia como expressão artística, cujo conteúdo, em alguns casos, é completado por uma legenda reveladora. Em um segundo nível, há o grupo de fotografias em que o próprio Mário e suas companheiras de viagem surgem como personagens do relato de viagem, a título de ilustração de um estado de espírito ou de exposição de caráter pessoal sobre a paisagem. Este é o caso destes clichês, em que o escritor dança com Dolur (Fig. 4) e no segundo, em que está caracterizado de indígena (Fig. 5).

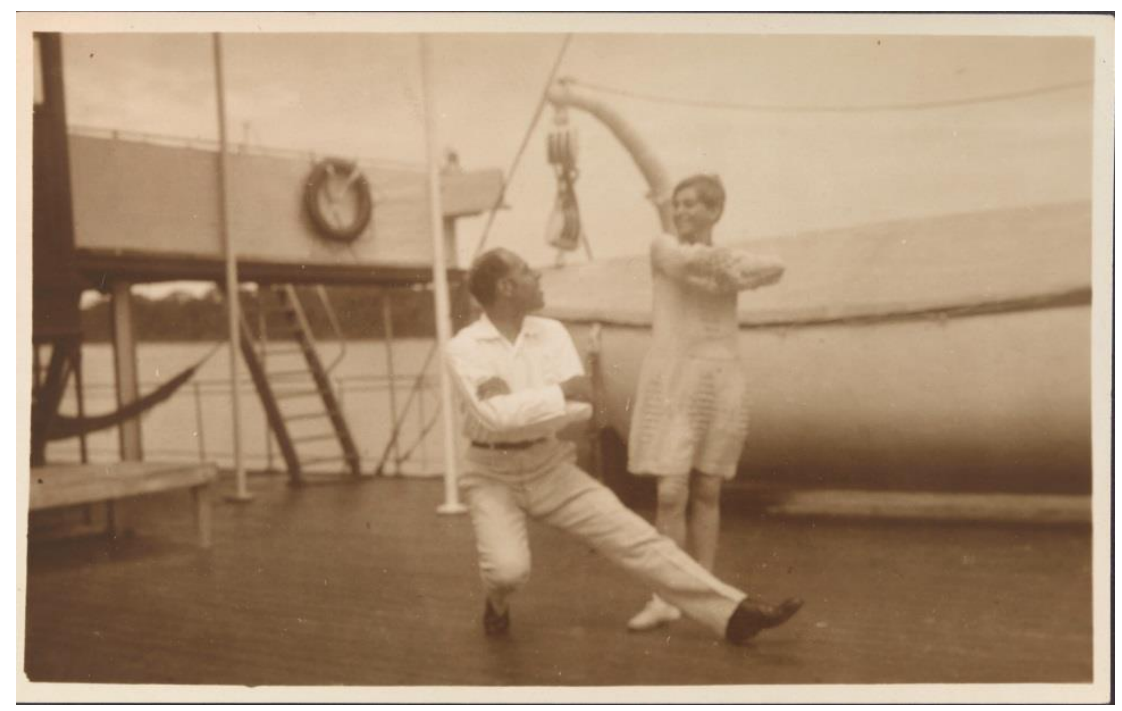

Fig. 4 


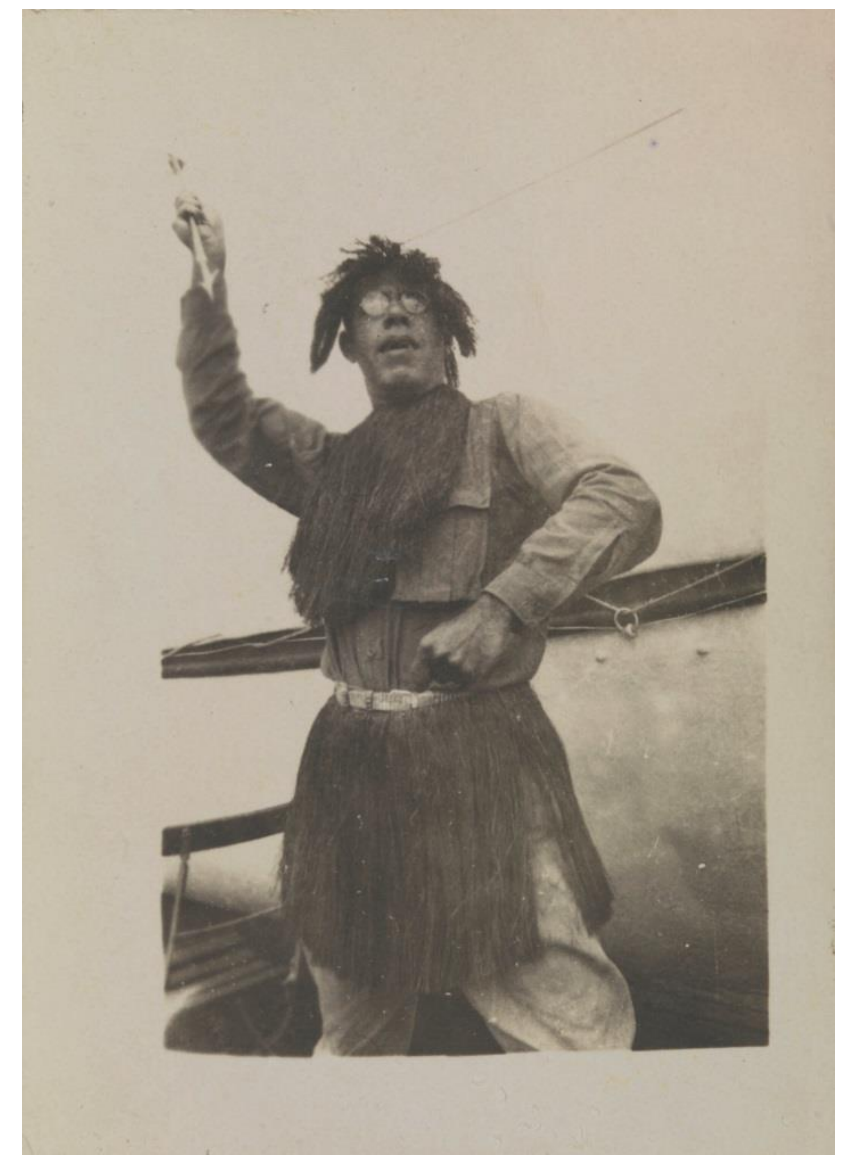

Fig. 5

E, por fim, há ainda as fotos do Mário de Andrade etnólogo que, em busca de um olhar brasileiro, dialoga com o relato de historiadores e viajantes, registrando os tipos físicos, a natureza e manifestações do folclore nacional, como se pode constatar no registro em anexo de uma procissão em Santarém, no Pará (see Fig. 6) e na fotografia de um porto de lenha em Assacaio (AM), com caboclos e indígenas (see Fig. 7).

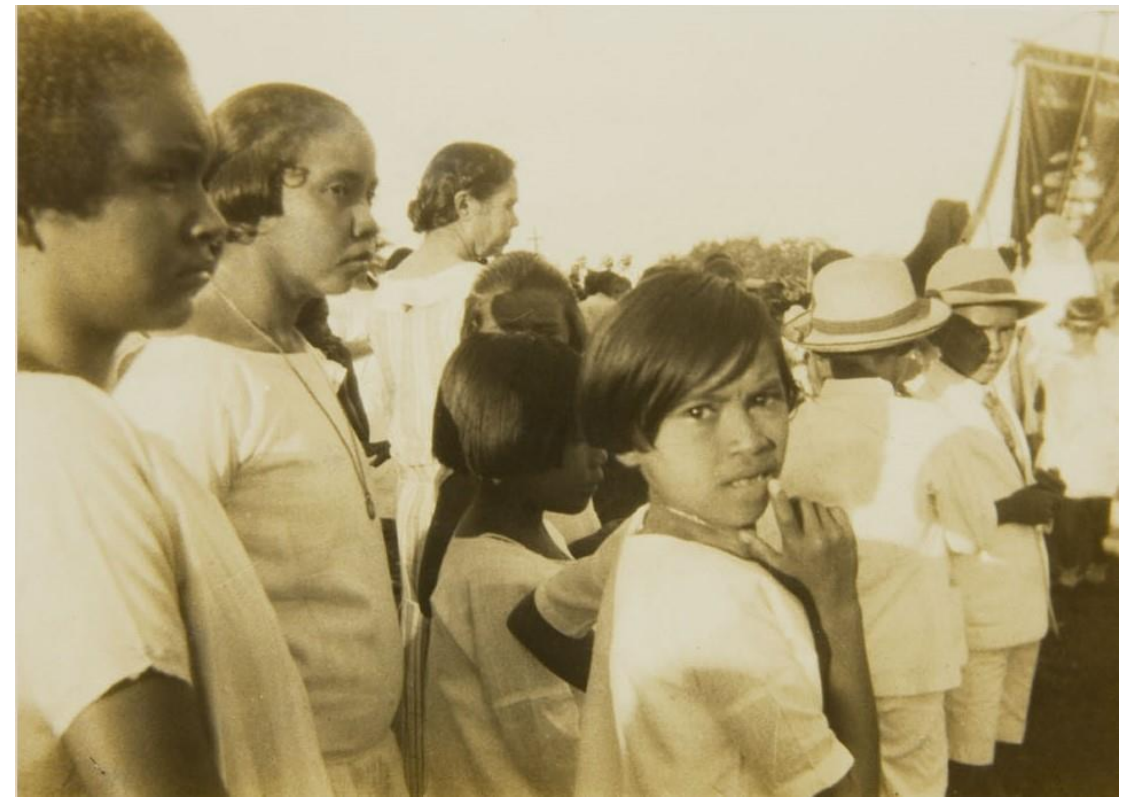

Fig. 6 


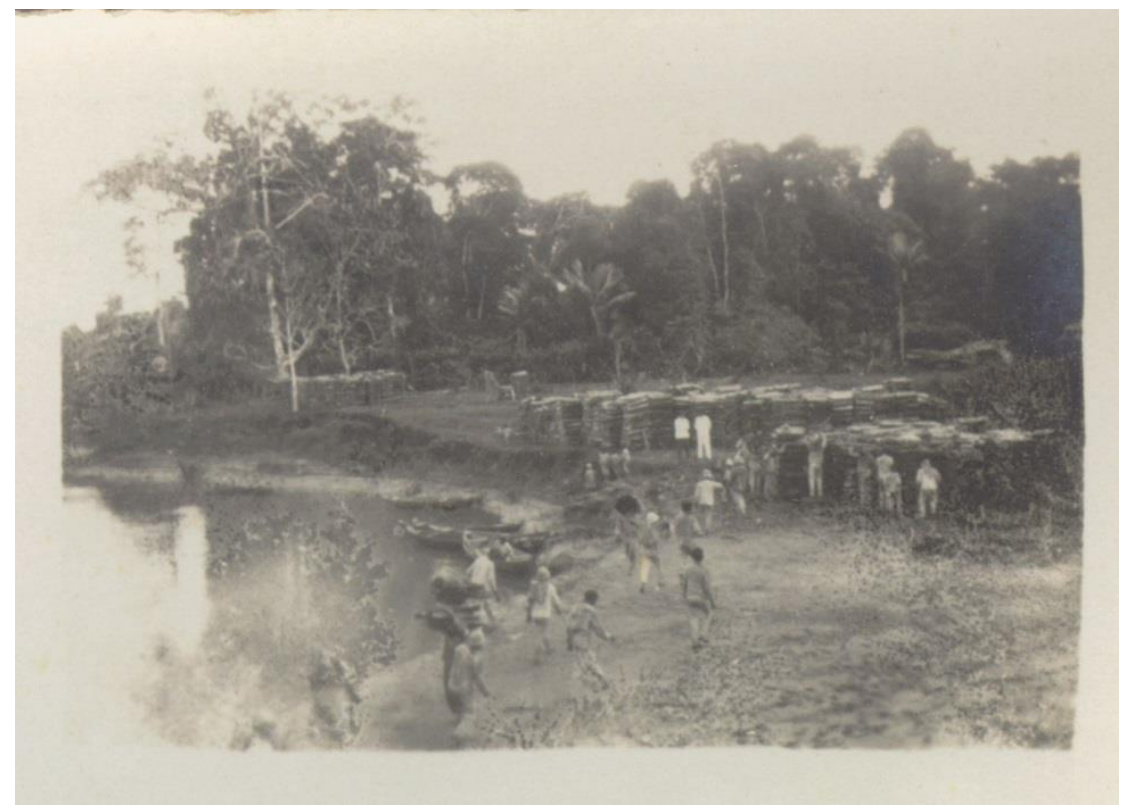

Fig. 7

É de se notar que embora fosse originário de São Paulo, a metrópole capitalista do país, Mário de Andrade tinha a constante preocupação em apreender a lógica interna de funcionamento das culturas locais. Assim é que, ao contrário dos viajantes usuais da Amazônia, que tendiam a perceber as populações autóctones como fauna exótica, o escritor paulista os fotografou em cenas cotidianas, banais, conferindo-lhes o direito à normalidade.

Porém, a marca do turista aprendiz é sem dúvida a estetização do real. O registro de um tarrafeiro, que Mário de Andrade legendou de «Futurismo pingando » é um exemplo característico da experimentação artística de uma linguagem contemporânea. No lugar de fotografar a ação do pescador que joga a sua rede (tarrafa), o fotógrafo modernista está mais preocupado em captar o jogo de luz e sombra que o movimento produz.

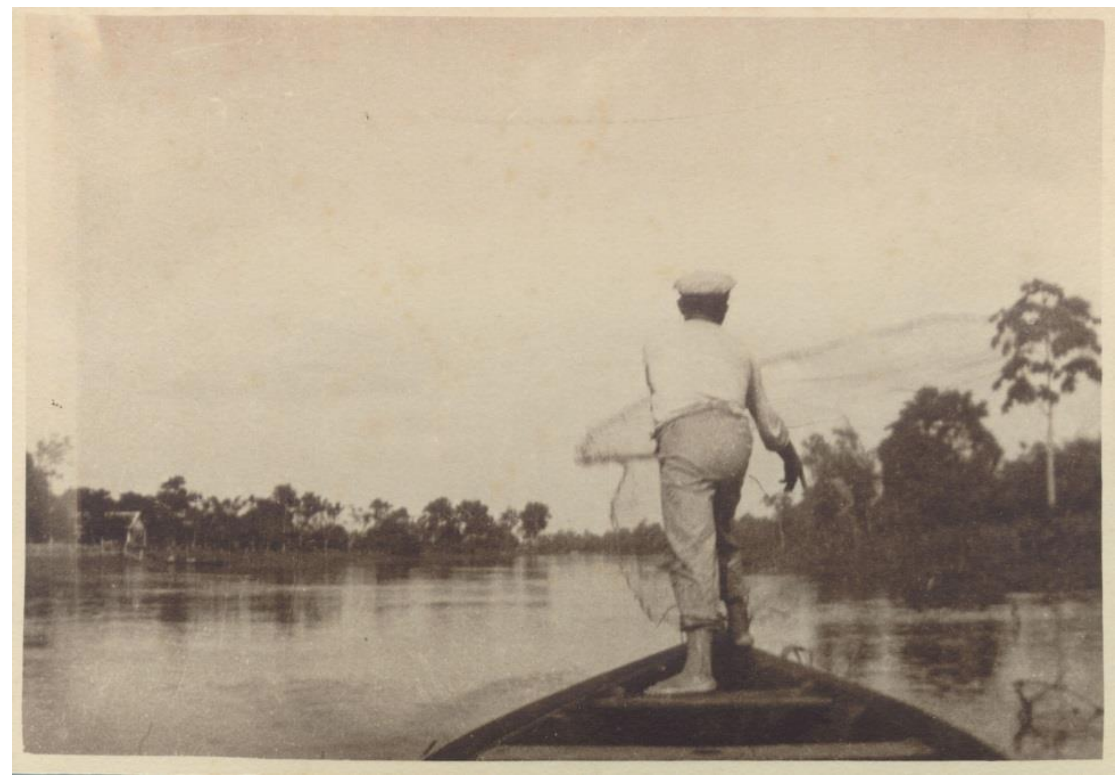

Fig. 8

É curioso aproximar esta fotografia deste registro, publicado pela já citada revista de arte contemporânea que Mário de Andrade assinava, Der Querschnitt, com soldados alemães 
trabalhando no castelo de Paretz. Nota-se que ambas adotam o mesmo ângulo, ou seja, as pessoas são fotografadas pelas costas e são flagradas no meio de uma ação. Esta edição da revista é de setembro de 1925

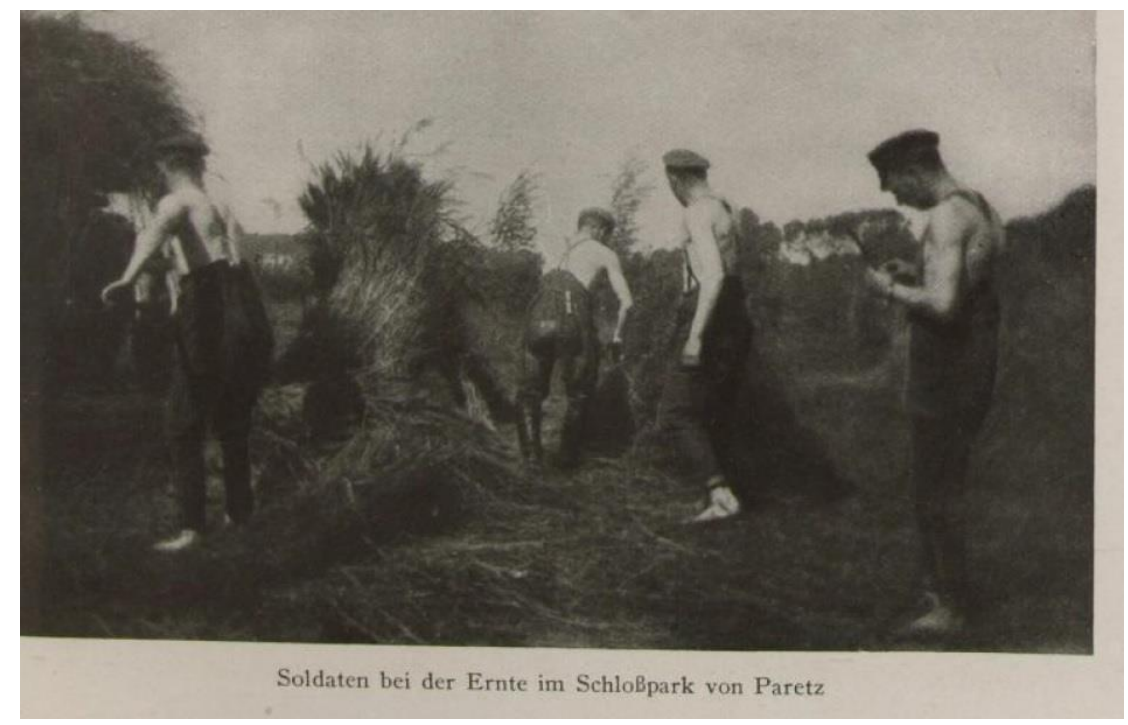

Fig. 9

https://www.arthistoricum.net/werkansicht/dlf/73165/21/0/\#

No início do século XX, a fotografia - objeto situado na intersecção da arte e do mundo real - suscitava vários questionamentos. Walter Benjamin, no seu ensaio sobre a história da fotografia, ao compará-la à pintura, em particular, aos retratos de pessoas anônimas que, uma vez transformadas em obra de arte, desapareciam. O que passava a existir era um quadro. Já no caso da fotografia, há qualquer coisa de misterioso que conecta aquele objeto retratado ao olhar que o observa - em permanente conexão, como notou Benjamin:

\begin{abstract}
A técnica mais exata pode dar às suas criações um valor mágico que um quadro nunca mais terá para nós. Apesar de toda a perícia do fotógrafo e de tudo o que existe de planejado em seu comportamento, o observador sente a necessidade irresistível de procurar nessa imagem a pequena centelha do acaso, do que e agora, com a qual a realidade chamuscou a imagem, de procurar o lugar imperceptível em que o futuro se aninha ainda hoje em minutos únicos, há muito extintos, e com tanta eloquência que podemos descobri-lo, olhando para trás. A natureza que fala à câmara não é a mesma que fala ao olhar; é outra, especialmente porque substitui a um espaço trabalho conscientemente pelo homem, um espaço que ele percorre inconscientemente (Benjamin 1986, 96).
\end{abstract}

Essa aproximação entre o inconsciente e a fotografia é um aspecto extremamente relevante para a experiência modernista e, não à toa, que uma tal forma de expressão atraiu Mário de Andrade, que nos legou um conjunto de imagens que visam recriar a paisagem retratada. Ao buscar trabalhar artisticamente suas imagens, o autor nos permite vislumbrar um pouco do seu olhar criativo. Assim, a imagem dos meninos indígenas fotografados por Mário de Andrade, em um longínquo dia de 1927 nos chega com esta superposição visual: o que nos interpela é precisamente a atualidade da foto, é o olhar dos meninos indígenas que fixam a câmara, eternizando uma presença que se revela continuamente. Nesta foto, Andrade inseriu a seguinte legenda: «o homem que tirou fotografia da gente », invertendo, assim o papel: o 
fotógrafo é quem seria a figura exótica, e não os meninos nativos, pois eles pertencem àquele ambiente, ao contrário do viajante.

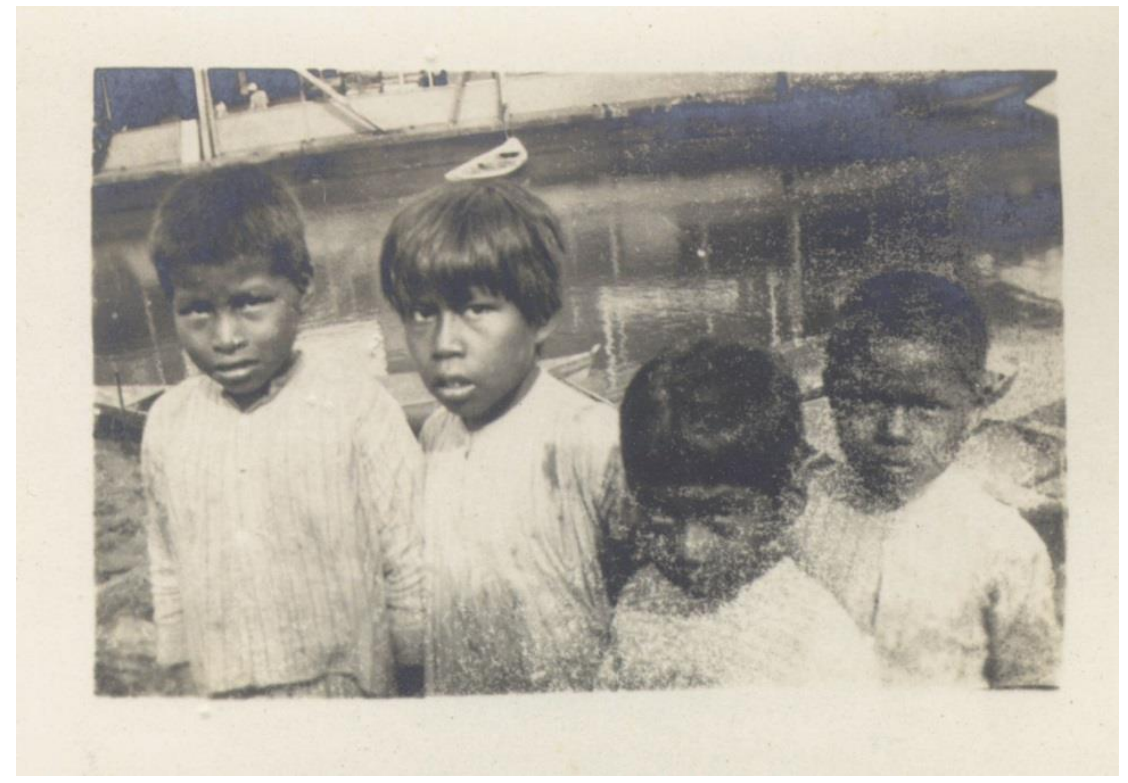

Fig. 10

O fotógrafo intencionalmente afasta-se da pura representação do real, com vias a criar uma narrativa que se apropria do modelo, seja desconstruindo, seja construindo sentidos. A título de exemplo, veja-se esta imagem dos mastros dos barcos em um porto da Amazônia.

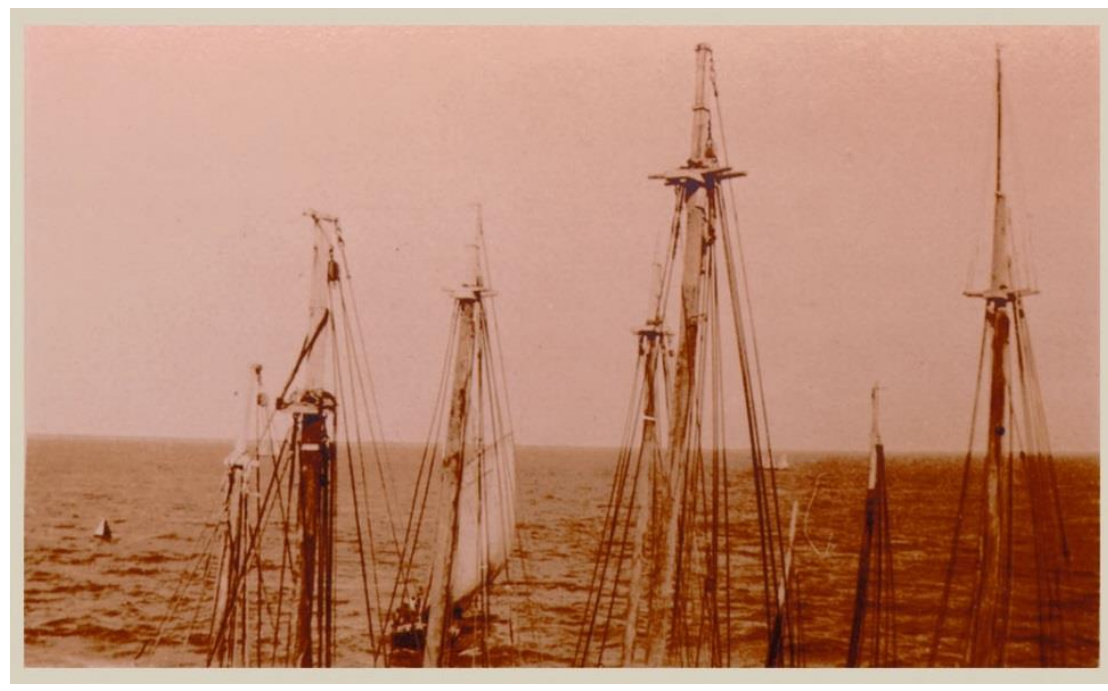

Fig. 11

No caso, o que importou ao fotógrafo, foi o efeito causado pelos mastros. Mais uma vez, vale a pena comparar com estas imagens de pinturas publicadas na edição de janeiro de 1927 na revista Der Querschnitt. 


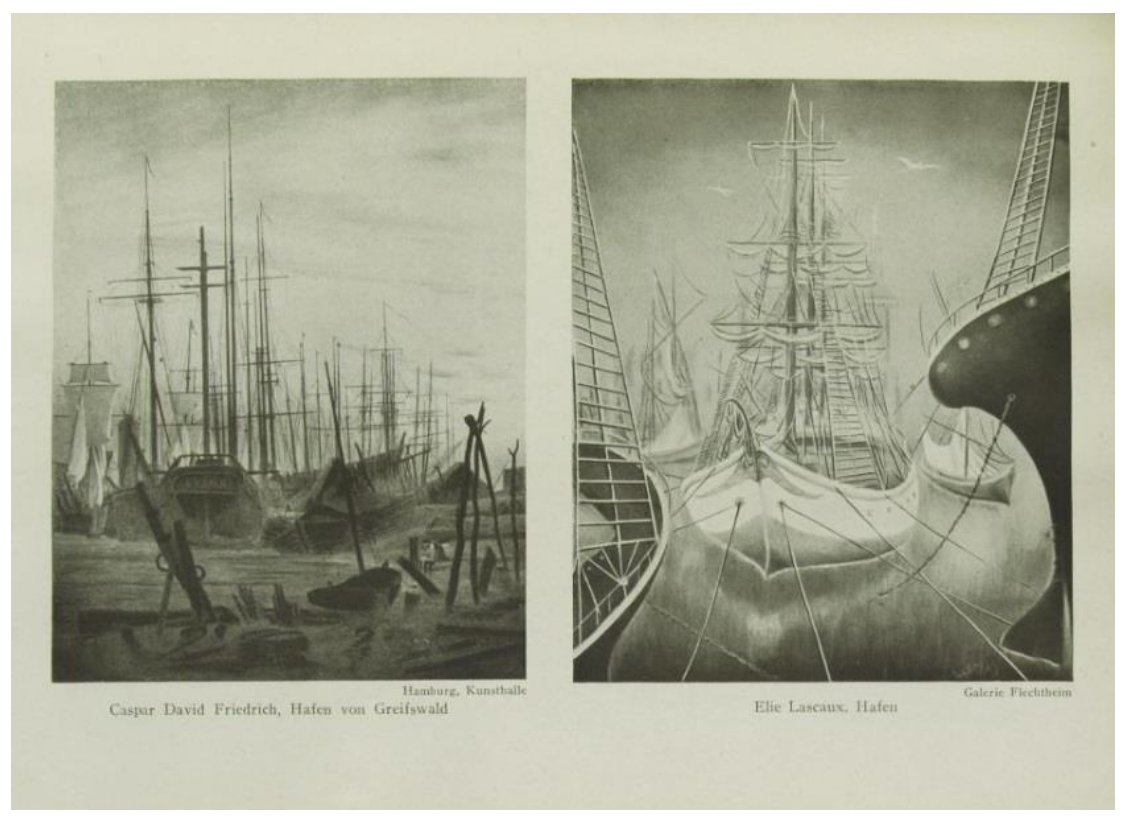

Fig. 12

https://www.arthistoricum.net/werkansicht/dlf/73206/87/\#

Aqui é interessante aproximar o processo criativo fotográfico de Andrade com o seu processo literário, pois se trata de um procedimento de reconstrução da imagem no qual os objetos retratos são descontextualizados, uma vez que não se pode ver os barcos, mas apenas supor que eles estejam lá. Ora, tal procedimento é igualmente notado nos textos do escritor, em que os elementos externos, da natureza, da geografia e da paisagem, são retrabalhados, com fins estéticos.

No seu ensaio sobre a fotografia, Susan Sontag afirmou que a fotografia é também uma forma de recusa do real: «A way of certifying experience, taking photographs is also a way of refusing it - by limiting experience to a search of the photogenic, by converting experience into an image, a souvenir ». (Sontag 2008, 19) Está claro, Sontag está se referindo a um aspecto do viajante moderno que, ao registrar as paisagens e as pessoas que observa, precisamente as anula, porque o seu objetivo é unicamente decorativo, é ter um souvenir de tudo o que viu. Entretanto, no caso da iniciativa de Mário de Andrade, pode-se deduzir que o escritor-fotógrafo utiliza a sua câmera para converter a experiência factual em imagem artisticamente convertida, desmanchando propositalmente a narrativa imagística usual da região amazônica, que tende para o aspecto de catalogação do real (sobretudo com as imagens de etnólogos, naturalistas, botânicos etc.).

Já no seu esboço de prefácio, o escritor discorre sobre a sua incapacidade, durante as suas viagens, de estabelecer uma crônica convencional dos hábitos e costumes locais:

Compra duma rede de linha, feita no Maranhão. O que me decidiu na compra de tal rede, o que fez que eu gostasse mais dela do que das outras não foi nenhuma qualidade maranhense de fabrico ou maior utilidade do objeto, mas a sua combinação de cores, em azuis baixos e terras, apresentar muita coincidência com certas combinações de cores, sábias e discretas, usadas pela pintura cubista. «Um Braque!», exclamei e comprei a rede. (Andrade 2015, 48)

Com relação aos registros textuais produzidos durante a viagem, percebe-se algumas características de um autor modernista e o próprio Mário afirma: 
Durante esta viagem pela Amazônia, muito resolvido a... escrever um livro modernista, provavelmente mais resolvido a escrever que a viajar, tomei muitas notas como vai se ver. (Andrade 2015, 48)

No prefácio que deixou escrito para o futuro relato de viagem, o autor adverte que o livro em questão será um «antirrelato », no sentido em que o objetivo é produzir uma narrativa esteticamente elaborada, algo além de uma simples narrativa acerca das regiões visitadas. Ao longo do diário, percebe-se, assim como nos registros fotográficos, a preocupação em ficcionalizar as experiências. Assim, quando os viajantes estavam a caminho da Amazônia, passando por Maceió, ele relata um sonho:

\begin{abstract}
Sonhei assim:
Com muito cuidado, escrevi um discurso em tupi pra dizer a nossa saudação a todos, quando estivéssemos entre os índios. Encontramos uma tribo completa bem na foz do Madeira, não faltava nem escrivão nem juiz-de-paz pra eu me queixar se alguém bulisse com a Rainha do Café. ${ }^{1}$ Vai, recitei o meu discurso, que aliás era curto. Mas desde o princípio dele os índios principiaram se entreolhando e fazendo ar de riso. Percebi logo que era inútil e que eles estavam com uma vontade enorme de comer nós todos. Mas não era isso não: quando acabei o discurso, todos se puseram gritando pra mim:

- Tá errado! tá errado! (Andrade 2015, 68)
\end{abstract}

Neste trecho do diário, nota-se que o narrador relata um não-acontecimento, um fato sem existência real, que é um sonho. E, no seu conteúdo, de modo muito irônico, o narrador teme que eles serão vítimas da antropofagia dos indígenas, o que se revelou incorreto: ele estava falando a língua errada. Ou melhor: ele errou duas vezes, ao apostar na civilidade dos indígenas e também na selvageria. Essa lógica derrisória, típica de Mário de Andrade, para, ao fim, concluir com um desacerto perene, entre eles (os visitantes, representantes da civilização) e os indígenas (os autênticos filhos da terra). E aqui, cabe uma correlação do diário de viagem com Macunaíma, publicado no ano seguinte, em 1928.

Com relação aos registros textuais produzidos durante a viagem, percebe-se que são produtos de um autor modernista, antes de mais nada. Isso quer dizer que a escrita e a organização dos eventos são fragmentárias e há uma busca permanente de abrasileirar a língua, seja através de neologismos, seja através da incorporação de aspectos da oralidade na língua escrita, pois um dos objetivos dos modernistas brasileiros era revelar e promover um falar mais característico do Brasil. As expressões em idiomas estrangeiros incorporam essa mesma roupagem nacional. Assim, por exemplo, ele se refere à câmera Kodak que adquiriu como Codaque (a letra $\mathrm{K}$ sendo uma importação na língua portuguesa) e cria o neologismo fotar (no lugar de fotografar).

Macunaíma: de lenda amazônica a herói sem caráter

Em 1928, foi publicada a narrativa Macunaíma, considerada o marco do movimento modernista brasileiro, livro em que Mário de Andrade faria a síntese do país e obra em aberto, na qual fez constantes modificações nas edições que se sucederam, até a morte do autor, em 1945. A escrita de Macunaíma teria se iniciado em 1926, logo após o autor adquirir quatro dos cinco volumes da obra do etnólogo alemão Theodor Koch-Grünberg, Vom Roraima zum

\footnotetext{
${ }^{1}$ Outro apelido de Olívia Guedes Penteado, que era membro da elite produtora de café, em São Paulo.
} 
Orinoco, resultado de alguns anos de trabalho junto a indígenas na Amazônia2. Foi através destes relatos que Mário de Andrade descobriu o personagem das lendas indígenas dos Taulipáng, chamado de Makunaíma que, segundo Koch-Grünberg, era um semideus muito humano, egoísta, mentiroso e muito pouco confiável. De acordo com o explorador alemão, o nome do personagem é constituído do prefixo maku, que significa "mau" e o sufixo ima, que significa "grande". Makunaíma seria, então, "o grande mau”. Tais características em negativo serviram como uma inspiração para a criação do personagem Macunaíma, o anti-herói brasileiro, como explica Telê Ancona Lopez, na introdução da edição comentada do livro que ela organizou:

\begin{abstract}
Lidos esses mitos fundamentais, conscientizando o propósito literário, um projeto particular cresce dentro do projeto maior que, no experimentalismo, o modernista sistematiza: a "literatura de circunstância", presa ao aqui e ao agora, convalida a dignidade do fazer poético popular e da criação do selvagem, busca subsídios na música e quer, como instrumento de expressão, a fala brasileira. Na "literatura de circunstância", reúne dados de todo Brasil, mas, propositalmente os mistura, desregionalizando, para privilegiar uma ideia de conjunto (Andrade 2015, Introdução, XXVI).
\end{abstract}

Ora, é importante notar que as narrativas de viagem funcionaram como importantes fontes para a prosa brasileira, no momento de formação que representou o Romantismo brasileiro no século XIX. No caso do Modernismo, para se conhecer melhor o país que se planejava retratar, muitos intelectuais foram levados a tornaram-se viajantes-observadores eles mesmos, verdadeiros pesquisadores da cultura brasileira e é, talvez, a encarnação desse viajante etnólogo que Mário de Andrade exemplifica. Contudo, o escritor estava consciente das suas limitações enquanto pesquisador, como confessa neste trecho do esboço de um primeiro prefácio ao que o seu livro de crônicas de viagem, no qual assume que a sua subjetividade interferia diretamente na paisagem visitada e nas coisas que observava, questionando-se, efetivamente, sobre a sua capacidade de aprendizado, que seria, teoricamente, a finalidade última da viagem:

$\mathrm{Na}$ verdade eu estou viajando muito em torno de mim mesmo e, aplicando egoistamente as minhas experiências em vez de me enriquecer de novas. Às vezes me vem mesmo a ideia de que eu talvez seja um «errado», porém é impossível eu aceitar esse qualificativo. Simplesmente porque eu me sinto feliz; feliz mesmo nesta infelicidade atual de estar viajando. (Andrade 2015, 48)

Ora, note-se que o livro que Mário de Andrade revisava, enquanto viajava pela Amazônia era precisamente Macunaíma, lançado no ano seguinte, em 1928. Portanto, é deste modo que se deve compreender as viagens etnológicas de Mário de Andrade pelo país, no sentido de aferir como a cultura nacional se constituía, amalgamando as influências as mais variadas. É, talvez, este reconhecimento que torna a viagem deste intelectual multifacetado tão relevante. As narrativas de viagem de ordem científica e supostamente objetivas pendem para o plano pessoal, da relação do sujeito criador como colecionador das variantes da cultura nacional, a fonte de inspiração transformada pela subjetividade do artista.

\footnotetext{
2 Entre 1898 e 1924, o antropólogo alemão Theodor Koch-Grünberg (1872-1924) participou de quatro expedições à região amazônica. Essas expedições resultaram em várias publicações, das quais se destacam: Dois anos entre os indígenas: viagens no noroeste do Brasil, 1903-1905 e a coletânea de cinco volumes intitulada Vom Roroima zum Orinoco, publicada a partir de 1917.
} 
O que se percebe na leitura de $O$ Turista Aprendiz, é a aproximação dos dois projetos: a narrativa rapsódica do anti-herói brasileiro e o diário de viagem que traz relatos fantasiosos, muitos dos quais são encontrados em Macunaíma. Neste livro, o protagonista é qualificado como o « herói sem nenhum caráter ». Trata-se de uma definição ambígua, pois significa uma pessoa não confiável e também alguém que não tem um só caráter definido, mas muitos.

Neste aspecto, o personagem é uma alegoria do brasileiro não tem pontos de referência fixos, pois sua cultura é jovem, maleável e o Brasil ainda é uma nação a ser construída. Também no dia 11 de julho do diário de O Turista Aprendiz, Mário ressalta esse caráter indefinível, relatando um diálogo do narrador com um menino, por ele intitulado de «Sintaxe»:

Quando íamos em busca do marco de limites, perguntei ao descalcinho que ia ao meu lado, cansado de me olhar:

- É longe?

- É não.

- Você mora aqui?

- Moro não.

- Então nasceu no estado do Amazonas?

- Nasci não.

Me deu uma canseira! (Andrade 2015, 157)

Em um episódio de Macunaíma, o herói saiu da Amazônia e foi para São Paulo e mente para os outros dizendo que caçou dois veados, o que não era verdade. As pessoas descobrem e vão até o quarto dele tomar satisfação:

Então os vizinhos perceberam que tudo era mentira do herói, tiveram raiva e entraram no quarto dele pra tomar satisfação. Macunaíma estava tocando numa flautinha feita de canudo de mamão. Parou o sopro, aparou o bocal da flautinha e se admirou muito sossegado:

- Pra quê essa gentama no meu quarto agora!....Faz mal pra saúde, gente!

Todos perguntaram pra ele:

- O que foi mesmo que você caçou, herói?

- Dois viados mateiros.

Então os criados as cunhãs estudantes empregados-públicos, todos esses vizinhos principiaram rindo dele. Macunaíma sempre aparando o bocal da flautinha.

A patroa cruzando os braços ralhou assim:

- Mas, meus cuidados, pra que você fala que foram dois viados e em vez foram dois ratos chamuscados?

Macunaíma parou assim os olhos nela e secundou:

- Eu menti. (Andrade 1997, 95)

Neste caso, o discurso do descalcinho é feito na lógica da negação, assim como a mentira de Macunaíma. Mais uma vez aqui o autor deseja ressaltar o caráter maleável do brasileiro: ao invés de afirmar e comunicar, ele usa a fala para negar e ocultar, ou para afirmar pela exclusão.

Na edição comentada de Macunaíma, Telê Ancona Lopez lança a possibilidade que o último capítulo de Macunaíma, intitulado «Ursa Maior » pode ter sido sugerido ao autor na viagem à Amazônia, pois no diário do dia 12 de junho ele trata da constelação: 
A noite já entrara quando portamos num porto de lenha. Céu do Equador, domínio da Usa Maior, o grande Saci...Estávamos excitadíssimos, com vontade até de crimes. Atrás, na lagoa, ficava o lugarejo Caiçara, onde tinha festa. Fomos lá e encontramos o bailado da «Ciranda», que vi quase inteiro, registrei duas músicas numa caixa de cigarro, e tomei umas notas como pude, tinha esquecido o livro de notas. (Andrade 2015, 106)

No livro, o herói vira a constelação:

Então Pauí-Pódole teve dó de Macunaíma. Fez uma feitiçaria. Agarrou três pauzinhos jogou pro alto fez em encruzilhada e virou Macunaíma com todo o estenderete dele, galo galinha gaiola revólver relógio, numa constelação nova. É a constelação da Ursa Maior.

Dizem que um professor naturalmente alemão andou falando por aí por causa da perna só da Ursa Maior que ela é saci...Não é não! Saci inda para neste mundo espalhando fogueira e trançando crina de bagual...

A Ursa Maior é Macunaíma. (Andrade 1997, 166)

No diário, no dia 5 de julho, há um registro sobre as Amazonas que, na verdade, dá-se na base da inversão, pois o autor escreveu o sentido entre parênteses: "sátira à mulher moderna ». Pois este registro traz muitas semelhanças com a descrição das mulheres da cidade, na «Carta pras Icamiabas » de Macunaíma. A título de comparação, eis dois trechos, o primeiro do diário:

Gostavam muito de falar palavras-feias que era um jeito ostensivo de mostrar liberdade e independência.

Estavam numa fase de transição abandonando a lei antiga. Mas ainda não tinham nenhuma lei moderna, e era aquela meleca.

Gostavam de mostrar erudição. Esportivas demais e fortíssimas. Não só queimavam um seio agora, mas não tinham seio nenhum como Antinous. (Andrade 2015, 144)

E este trecho da carta:

E muito há que vos diga sobre o jeito com que cortam as comas, de tal maneira gracioso e viril, que mais se assemelham elas a efebos e Antínous, de perversa memória, que a matronas de tão directa progénie latina. Todavia, convireis conosco, no desacerto de longas tranças por cá, si atenderdes ao que mais atrás ficou dito; pois que os doutores de São Paulo não derribam as suas requestadas pela força, senão que a troco de oiro e de locustas, as ditas comas são de somenos, acrescendo ainda que assim se amainam os males, que tais comas acarretam, de serem moradia e pasto habitual de insectos mui daninhos, como entre vós se dá. (Andrade 1996, 77)

Note-se a semelhança, não apenas do conteúdo, como na forma satírica entre estes dois textos. Em síntese, nota-se que a viagem à Amazônia do autor e os registros que dela resultaram estão inseridos no projeto estético global de Mário de Andrade. A Amazônia surge, assim, como parte da elaboração simbólica que o autor pretende encenar, seja em imagens, seja em textos. Dentro deste prisma, Mário de Andrade coloca-se em primeiro plano, como artista e intelectual, da representação que é feita.

Por fim, a relação do escritor com a viagem à Amazônia é um movimento que se dá em épocas diversas. Em primeiro lugar, na ocasião da viagem, apenas cinco anos após a Semana de 22, que lançou o grupo de modernistas brasileiros, em que o escritor estava 
inteiramente imbuído com o espírito revolucionário de ruptura da época e que se reflete na sua literatura e nas imagens que produz. E, em um segundo momento, nos anos 1940, quando, mais afastado dos anos revolucionários, o autor retorna ao material produzido para revisá-lo e modificá-lo.

Como se pode notar na biblioteca do escritor que consta no catálogo do IEB, Mário de Andrade leu diversos relatos de viagem sobre a Amazônia, como já foi mencionado anteriormente. Entre eles, está o de Louis Agassiz, cuja redação foi feita pela esposa do cientista. Em dado trecho deste relato, há uma descrição da pesca do peixe-boi, uma criatura extremamente dócil:

The Indians are very adroit in shooting the larger fish with the bow and arrow, and in harpooning some of the veritable monster of their rivers, such as the Peixe-boi («fishcow»), Manatee or Dugon, with the spear. [...] In the course of the day two «Peixe-bois» (Manatees) were brought in, also a Boto (porpoise), and some large specimens of Pirarucu (Sudis). All these are too clumsy to preserve in alcohol, especially when alcohol is so difficult to obtain and so expensive as it is here; but Mr. Agassiz has had skeletons made of them, and will preserve the skins of the Peixe-bois for mounting. (Agassiz 1875, 234-235)

Vê-se então, que duas décadas depois a sua viagem à Amazônia, à mesma ocasião em que redigiu o prefácio para o projeto de $O$ turista aprendiz, Mário de Andrade inseriu um trecho sobre o peixe-boi, que vale a pena ser retomado:

O que valeu mesmo a pena foi ver o peixe-boi. Come erva com muita educação, sem fazer bulha nenhuma e só entreabrindo a boca. Se falasse, eu mandava ensinar italiano a ele e o punha num restaurante obrigatório em São Paulo, pra ensinar aos meus patrícios a comer. Infelizmente não fala não. O peixe-boi é uma baleia que só por desânimo deixou de crescer mais. Tem uma cara parecida com a do hipopótamo e traz os olhos sempre debaixo d'água, com pudor. As nadadeiras são de uma espécie de metal prateado, da família das platinas, e delas se extrai uma graxa boa pra curar doenças do fígado, congestões, mordeduras de mosquito e espinhela caída. Pra contusões é tiro e queda. O peixe-boi bota ovos róseos que são chocados ao sol pela Municipalidade. Os filhotes saem munidos de asas pequeninas (que logo perdem) com as quais atingem as correntes do Amazonas e vão crescer no lago Lauricocha ${ }^{3}$, até a idade de razão. Apreciamos muito o peixe-boi. (Andrade 2015, 201)

Concluindo, os relatos de viagem à Amazônia de Mário de Andrade, tanto nos aspectos textuais, quantos seus registros fotográficos revelam muitos aspectos do processo criativo e da visão que este versátil intelectual tinha do Brasil. Em uma dinâmica de justaposição de diversas linguagens - diário de viagem, anotações, narrativas ficcionais, fotografia, poesia, encenação teatralizada etc. - , estes fragmentos nos chegam como um mosaico que constitui os sentidos simbólicos que o autor desejava reinterpretar ao seu modo. De maneira que, seria talvez mais correto dizer que, naquele ano de 1927, a Amazônia viajou até Mário de Andrade.

\footnotetext{
${ }^{3}$ O Lago Lauricocha se situa na Cordilheira dos Andes, no Peru. Os viajantes acreditavam que ele era a nascente do Amazonas, vide este trecho de Alexander von Humboldt, em descrição do rio Amazonas: “O Amazonas, pelo contrário é o mais largo de todos os rios; percorre uma extensão de mil e oitocentas léguas, desde o seu nascimento no lago Lauricocha até a embocadura”. (Humboldt 1950, 215).
} 


\section{Referencias}

Agassiz, Louis \& Agassiz, Elizabeth. 1875. Journey in Brazil. Boston: J.R. Osgood and company

Andrade, Mário de. 1942. O Movimento Modernista. Rio de Janeiro: Casa do Estudante do Brasil.

- 1966. Poesias completas. São Paulo: Martins.

- 1976. O turista aprendiz. Organizado por Telê Porto Ancona Lopez. São Paulo: Livraria Duas Cidades : Secretaria da Cultura, Ciência e Tecnologia.

- 1993a. A arte religiosa no Brasil. Organizado por Claudéte Kronbauer. São Paulo, SP: Experimento : Editora Giordano.

—. 1993b. Mário de Andrade: fotógrafo e turista aprendiz. Organizado por Telê Porto Ancona Lopez e Ana Maria Paulino. São Paulo: Instituto de Estudos Brasileiros da Universidade de São Paulo.

-1993c. Mário de Andrade: fotógrafo e turista aprendiz. São Paulo: Instituto de estudos brasileiros.

- 1994. Balanca, trombeta e battleship, ou, O descobrimento da alma. Organizado por Tele Porto Ancona Lopez. Sao Paulo, SP: Instituto Moreira Salles: Instituto de Estudos Brasileiros, USP.

—. 1997. Macunaíma: o herói sem nenhum caráter. Organizado por Telê Porto Ancona Lopez. Nanterre: ALLCA XX.

- 2015. O turista aprendiz. Organizado por Telê Porto Ancona Lopez.

Benjamin, Walter. 1986. Obras escolhidas. Vol. 1 Vol. 1. Traduzido por Sérgio Paulo Rouanet. São Paulo: Ed. Brasiliense.

Bosi, Alfredo. 2013. História concisa da literatura brasileira. São Paulo: Cultrix.

Campos, Haroldo de. 1992. "Da razão antropofágica: diálogo e diferença na cultura brasileira". In Metalinguagem e outras metas: ensaios de teoria e crítica literária, 1 vol.:311. São Paulo: Perspectiva.

Cândido, Antônio. 2017. Formação da Literatura Brasileira: Momentos decisivos. Rio de Janeiro: Ouro sobre azul.

Koch-Grünberg, Theodor. 2005. Do Roraima ao Orinoco. São Paulo: Editora UNESP: Instituto Martius-Staden.

Proença Filho, Domício. 1983. Estilos de época na literatura (através de textos comentados). $7^{\circ}$ ed. São Paulo: Ed. Atica.

Sodré, Nelson Werneck. 1964. História da literatura brasileira: seus fundamentos econômicos. Rio de Janeiro: Civilização brasileira.

Sontag, Susan. 2008. On photography. London: Penguin Books. 